\title{
O Impacto dos Mecanismos de Urgência no Sucesso Presidencial. Uma Análise do Caso Argentino à Luz da Experiência Brasileira*
}

\author{
Rafael de Paula Santos Cortez
}

\section{INTRODUÇÃO}

\begin{abstract}
publicação do trabalho de Shugart e Carey (1992) levantou uma A importante agenda de pesquisa, ainda não resolvida, no interior da literatura institucionalista, particularmente nos trabalhos que focalizaram o desempenho das democracias presidencialistas. Se é verdade que o presidencialismo tem desempenho distinto em virtude da combinação com as demais variáveis do arcabouço institucional de um sistema político, o que explicaria o desempenho governativo do Executivo?
\end{abstract}

Grosso modo, há na literatura dois tipos de explicação para o desempenho do presidencialismo. A primeira corrente centra o foco de análise no momento eleitoral. Em outras palavras, é o processo de competição política e, particularmente, as variáveis que condicionam esse momento da dinâmica política que explicariam a dinâmica das relações Executivo-Legislativo. Nesses termos, o número de partidos (Shugart e Carey, 1992; Mainwaring e Shugart, 1997; Cox e McCubbins, 2001;

*Este artigo é parte da minha dissertação de mestrado As Relações Executivo-Legislativo na Argentina à Luz da Experiência Brasileira, defendida no Departamento de Ciência Política da Universidade de São Paulo - USP, em 2005. Agradeço os comentários de Fernando Limongi (orientador), Cláudio Couto e Maria D’Alva Kinzo, bem como aos pareceristas anônimos de $D A D O S$. As falhas remanescentes são de minha inteira responsabilidade.

DADOS - Revista de Ciências Sociais, Rio de Janeiro, Vol. 50, nº3, 2007, pp. 579 a 609. 
Morgenstern, 2004); o calendário eleitoral (Shugart e Carey, 1992; Cox e McCubbins, 2001); e o tipo de lista eleitoral (Carey e Shugart, 1995; Cox e McCubbins, 2001) seriam as variáveis centrais para a definição da capacidade governativa do Executivo.

Em contrapartida, uma série de estudos voltou a atenção para o interior da organização do processo decisório. Essa corrente analítica destacou a importância da distribuição dos poderes de agenda no processo de formulação e discussão da produção legislativa. Aqui, o desempenho do governo está associado ao grau de centralização do processo decisório medido, basicamente, pela capacidade de iniciar o processo de alteração do status quo, bem como os controles sobre os mecanismos que permitiriam a alteração do timing do processo legislativo (Figueiredo e Limongi, 1999; 2000; Cheibub e Limongi, 2002; Cheibub, Przeworski e Saiegh, 2002; Santos, 2003) e o padrão da formação dos gabinetes ministeriais (Amorim Neto, 2006).

Minha leitura é a de que o debate acerca da performance do presidencialismo na América Latina não deu a devida importância à análise das regras que determinam os trabalhos legislativos em perspectiva comparada. Esses trabalhos seguem uma tradição iniciada pelos modelos da conexão eleitoral (Mayhew, 1974; Cain, Ferejohn e Fiorina, 1987) na qual a estrutura interna do Legislativo é tomada como variável dependente $^{1}$, ou seja, é o modo como se dá a conexão eleitoral que define como serão estruturados os trabalhos legislativos. Em outros termos, as análises institucionalistas têm concentrado seus esforços principalmente nas chamadas macroinstituições do sistema político.

Este artigo pretende discutir a influência dos mecanismos de controle de agenda, particularmente o de urgência no sucesso presidencial do sistema político argentino. Pretendo mostrar que a análise das microinstituições que regulam os trabalhos legislativos oferece um diagnóstico distinto daqueles decorrentes das análises que centram seu foco na conexão eleitoral sobre a capacidade governativa das democracias presidencialistas. Meu argumento é que as baixas taxas de sucesso do governo argentino decorrem da falta de controle dos mecanismos de tramitação especial para seus projetos de lei. Dessa forma, o governo é incapaz de minimizar a atuação das comissões, o que torna mais custosa a aprovação dos seus projetos.

A estratégia aqui utilizada é entender a organização do processo Legislativo como variável independente. Esta perspectiva analítica é mino- 
ritária nos estudos sobre o funcionamento do presidencialismo em perspectiva comparada, sendo as objeções metodológicas contrárias a ela neste trabalho de natureza teórica e empírica. A crítica de natureza teórica decorre, fundamentalmente, da clássica objeção levantada por Riker sobre o suposto caráter endógeno das instituições, ou seja, regras do jogo não poderiam ter status explicativo, pois seriam epifenômenos das relações de poder entre os atores. Dessa forma, elas não teriam estabilidade no tempo e sofreriam do mesmo problema de instabilidade característicos das preferências dos atores. No interior da literatura norte-americana sobre os estudos legislativos, alguns trabalhos adotam essa perspectiva analítica. Segundo Aldrich e Rohde (2000), as regras que comandam os trabalhos legislativos são endógenas, logo, não poderiam ser tomadas como dadas, mas deveriam ser explicadas. Esta é a perspectiva analítica que sustenta o trabalho comparado acerca da natureza do Poder Legislativo nas democracias presidencialistas contemporâneas, desenvolvido pelo comparativista Scott Morgenstern (2004). Do ponto de vista empírico, quanto à objeção do autor sobre a incapacidade de os poderes de agenda explicarem as evidências empíricas sobre desempenho governamental na América Latina, veremos que, de fato, as microinstituições podem contribuir para uma leitura mais precisa do desempenho das democracias presidencialistas.

O questionamento desenvolvido por Morgenstern não me parece suficientemente convincente para justificar a ausência da organização legislativa como variável independente nas análises comparativas. No limite, nos termos do argumento do autor, teríamos uma regressão ao infinito e seria preciso explicar a emergência de toda e qualquer regra. Diermeier e Krehbiel (2003) argumentam que existem duas agendas de pesquisa no interior do neo-institucionalismo: teorias institucionais (instituições são variáveis independentes) e teoria das instituições (instituições são variáveis dependentes). Seguindo Diermeier e Krehbiel, não haveria qualquer objeção em tratar as variáveis relativas à organização interna do Legislativo como variáveis independentes. Trata-se de uma opção analítica.

Tal opção metodológica nos permite escapar do suposto normativo que informa o debate sobre as relações Executivo-Legislativo em sistemas presidencialistas. Esse antagonismo entre os poderes é decorrente do foco exclusivo nas macroinstituições do processo político. De fato, estas macroinstituições importam para o desempenho dos sistemas políticos, contudo, as microinstituições que regulam o processo deci- 
sório definem incentivos e punições que importam para o padrão legislativo de um sistema político. Em outros termos, não podemos inferir o comportamento dos atores políticos exclusivamente a partir das macroinstituições (Cox e McCubbins, 1993; Figueiredo e Limongi, 1999; Cheibub e Limongi, 2002; Santos, 2003).

O objetivo central deste estudo é contribuir para a literatura comparada buscando preencher uma lacuna no que diz respeito às análises sobre a natureza do processo legislativo nas diferentes democracias presidencialistas. Como veremos posteriormente, essas variáveis não receberam, da literatura institucionalista, tratamento necessário. Meu objeto de análise será o caso argentino, e a base empírica utilizada será o processo de tramitação dos projetos convertidos em lei entre 1983 e 1998. A idéia é buscar compreender através de uma análise agregada algum elemento que permita entender o que explica a capacidade governativa do sistema político argentino. $\mathrm{O}$ foco estará centrado na capacidade de o Legislativo alterar os projetos de lei, bem como no controle dos mecanismos de alteração do trâmite legislativo.

A escolha de análise da tramitação dos projetos de lei na Argentina se deve aos achados da literatura brasileira acerca dos efeitos da organização do processo legislativo no desempenho governamental. Figueiredo e Limongi (1999) mostraram que a chance de um projeto de lei ser aprovado está positivamente associada à existência de alterações no ritmo da tramitação na fase de aprovação. Assim, a capacidade governativa do Executivo será mais efetiva quando ele estiver no controle dos mecanismos que regulam o processo legislativo. Nessa mesma linha de raciocínio, Santos (2003) mostrou que o mecanismo de urgência foi uma das principais alterações institucionais que permitiram explicar o desempenho do Executivo nos diferentes períodos democráticos do Brasil.

Este artigo está dividido em quatro seções. Na primeira, faço uma revisão da literatura comparada buscando mostrar os problemas analíticos advindos do foco exclusivo nas variáveis externas ao processo decisório (macroinstituições). Afirmo que o foco exclusivo nesse tipo de variável leva a concluir que há um conflito estrutural entre os dois poderes.

A segunda seção apresenta alguns indicadores empíricos presentes na literatura sobre sucesso presidencial no caso argentino à luz da experiência brasileira. Pretendo demonstrar empiricamente a importância 
da análise do processo legislativo. Os números para o caso argentino apontam para um paradoxo, a saber: as evidências empíricas mostram a coexistência de partidos altamente disciplinados com taxas de sucesso relativamente baixas, o que demonstraria a existência de mecanismos distintos na explicação da disciplina partidária e do sucesso presidencial.

A terceira seção traz os dados empíricos acerca do processo legislativo. A análise da tramitação dos projetos aprovados mostra que o Poder Legislativo tem capacidade de modificar os projetos, particularmente no interior das comissões, o que torna fundamental a existência de mecanismos para alterar o trâmite de um projeto, buscando contornar pontos de veto. Meus achados mostram que as alterações de timing não se concentram prioritariamente nos projetos de origem no Executivo, o que, por sua vez, explicaria as baixas taxas de sucesso demonstradas na segunda seção. Por fim, a conclusão resume os achados do estudo.

\section{UM BALANÇO DA LITERATURA COMPARADA}

Minha intenção em revisitar o debate institucionalista é demonstrar que as discussões sobre o funcionalismo dos sistemas presidencialistas estão baseadas no suposto de que são as variáveis no momento eleitoral que definiriam a natureza das relações Executivo-Legislativo e, por conseqüência, a capacidade legislativa dos governos. O foco nas variáveis externas do processo decisório leva a uma noção de contradição estrutural entre os poderes no presidencialismo, esse antagonismo necessário é o fator determinante para a paralisia decisória.

Essa tensão aparece no pioneiro trabalho de Shugart e Carey, expressa na forma Executivo, "nacional", versus Legislativo "local". O antagonismo está na base do segredo ineficiente. Trata-se de um conceito que expressaria a forma menos adequada de conjugar dois dilemas típicos da democracia: a eficiência e a representatividade, conforme definidos por Shugart e Carey (1992:3-4).

"O dilema central em regimes democráticos está relacionado com a divergência entre o que as assembléias representativas têm de melhor e o que o Executivo deve fazer para a democracia funcionar bem. Assembléias, ou pelo menos as câmaras baixas, pretendem ser representativas de toda a população. Uma típica assembléia democrática é eleita com o propósito de 'dar voz' aos interesses das localidades, das diversidades ideológicas ou divisões partidárias na polity e na sociedade. Ou seja, 
elas são, por natureza, paroquiais. O Executivo, em contrapartida, fica encarregado das políticas que afetam amplos interesses sociais, articulando objetivos nacionais" (ênfases e tradução do autor).

O argumento acerca da tensão entre os problemas é pensado com referências à conexão eleitoral. Assim, há uma associação entre balança horizontal e sistema eleitoral utilizado. O Executivo seria representante da totalidade da comunidade política, visto que o processo eleitoral ocorre em distrito nacional. Em contrapartida, os legisladores seriam representantes de localidades específicas (estados ou distritos). Assim, o Executivo aparece como defensor de políticas públicas que expressariam o "interesse nacional", ao passo que os legisladores teriam interesses em políticas públicas distributivistas, visando ao atendimento às bases particularistas. O lócus da efetividade seria o Poder Executivo, ao passo que o Poder Legislativo, a expressão da representatividade do sistema político nas democracias presidencialistas.

O conflito entre os poderes seria agravado ainda mais em decorrência do tipo de lista utilizada no pleito eleitoral. Nos sistemas de lista aberta, a conexão eleitoral se dá em bases pessoais, seja pelo estabelecimento de políticas locais, seja pelos atributos pessoais dos representantes. A conexão eleitoral partidária, via lista fechada, seria uma tentativa de conter esse freio localista inerente à atividade legislativa. Nota-se, contudo, que os partidos políticos não aparecem como pontes entre os poderes, mas como um mecanismo centralizador das barganhas do Legislativo, e que as preferências dos atores são exógenas ao processo de decisão das políticas, isto é, elas se formariam no momento anterior ao processo legislativo. Um sistema político, então, deveria combinar de maneira mais eficaz os princípios de eficiência legislativa e simetria na representação.

A diferença de performance dos sistemas presidencialistas advém da forma como tais princípios estão relacionados. Todavia, não fizemos referência aos instrumentos utilizados pelos analistas para mensurar o grau de representatividade e eficiência dos poderes. Shugart e Carey resolvem essa questão recorrendo ao número efetivo de partidos como o indicador mais favorável para resolver o problema de quantificação. Em suas palavras: "A utilização desse indicador [número efetivo de partidos] é justificada porque é a maneira mais simples de expressar, em um único número, tanto a eficiência eleitoral como o grau de representatividade" (1992:179, tradução do autor). Ora, o que se depreende 
desta passagem é que, no limite, a variável explicativa da performance do Poder Legislativo é o número de partidos ${ }^{2}$. Assim sendo, assume-se que instituições legislativas com maior número de partidos serão necessariamente mais paroquialistas do que sistemas com menor fragmentação. Se os legisladores buscam necessariamente atividades particularistas e o número de partidos mensura o número de grupos sociais que barganham recursos, então, sistemas com maior número de grupos sociais representados teriam o Poder Legislativo voltado para preocupações locais. Há, contudo, diversos supostos implícitos para que seja verdade que o número de partidos implique no número de "grupos sociais que barganham recursos". Não é o caso, aqui, de reconstruir os passos necessários para que essa relação se estabeleça. Cabe, no entanto, salientar que os autores "resolvem" de forma pouco fundamentada um ponto essencial do argumento acerca das relações Executivo e Legislativo, a ausência de explicações sobre o comportamento e os interesses específicos dos legisladores vis-à-vis o Executivo. Na verdade, essas lacunas analíticas decorrem do suposto básico que orienta a análise: o Executivo e os legisladores necessariamente possuem interesses diversos. Qual é o problema com essa variável explicativa?

O número de partidos efetivos põe o foco sobre a demanda, isto é, consegue captar o número de forças políticas que barganham recursos para um determinado grupo ou localidade; entretanto, nada nos diz sobre a oferta de recursos disponíveis, ou seja, não consegue definir a distribuição de poder entre os atores no processo de alocação de recursos que condiciona quem e em quais situações terão acesso a eles. Não há por que inferir, a priori, que todas as forças políticas terão seus pedidos atendidos. É necessário, então, buscar outras variáveis para entender os determinantes institucionais dessa barganha política. Trata-se da organização da estrutura legislativa tomada como variável independente (Cox, 1987; Huber, 1996; Figueiredo e Limongi, 1999). Um olhar estritamente externalista possui um limite explicativo para o entendimento da natureza do Poder Legislativo.

Esse argumento, presente em Shugart e Carey (1992), foi revisitado e modificado em alguns estudos posteriores sobre presidencialismo em perspectiva comparada. Cox e McCubbins (2001) procuram estabelecer uma distinção entre separação de poderes e separação de propósitos. No primeiro caso, trata-se de um mecanismo institucional inerente às democracias constitucionais, que não seria exclusividade dos sistemas presidencialistas. A separação de propósitos seria o determi- 
nante estrutural da tendência à paralisia decisória em regimes democráticos presidenciais. Ela resultaria de três fatores centrais: o calendário eleitoral, os incentivos do sistema eleitoral e a congruência de constituency (base eleitoral). Mais uma vez, a natureza das relações Executivo-Legislativo seria definida no momento anterior ao processo político.

Argumento de natureza semelhante está na base da tipologia dos legislativos na América Latina, desenvolvida por Cox e Morgenstern (2002). Os autores buscam mostrar que o Poder Legislativo não seria "disfuncional" para a efetividade política, mas assumiria um caráter eminentemente reativo. A variação encontrada seria decorrente das estratégias da ação presidencial, definidas a partir de uma leitura sobre o grau de cooperação do Legislativo. A variável fundamental, nesse diagnóstico, é a porcentagem de apoio do partido presidencial (idem:457). Em suma, a natureza do argumento não sofreu modificações. As variáveis externas ao processo decisório são tomadas como determinantes das relações entre Executivo e Legislativo.

A noção de um antagonismo estrutural entre os poderes tem suas origens nos federalistas e é a expressão do mecanismo de freios e contrapesos proposto pelos "pais fundadores". A lógica é que não deveria haver cooperação entre eles, mas, sim, competição, para que os perigos da tirania da maioria fossem evitados. Na versão moderna, a tensão institucional derivada dos modos de representação e, por conseguinte, da "vontade própria" de cada poder assumiu a forma do conflito Nacional versus Paroquial (Shugart e Carey, 1992). O foco exclusivamente nas macrorregiões não permitiria avaliações desamarradas desse princípio orientador do presidencialismo norte-americano.

\section{O PARADOXO ARGENTINO: LIÇÕES DA EXPERIÊNCIA BRASILEIRA}

Do ponto de vista da engenharia institucional, a literatura comparada (Shugart e Carey, 1992; Mainwaring e Shugart, 1997; Cox e Morgenstern, 2002) ressalta que, comparativamente ao caso brasileiro, o sistema político argentino possuiria os mecanismos necessários para garantir a eficiência da produção legislativa e, por conseguinte, da sua governabilidade. Se examinarmos essa literatura, veremos que a Argentina fez a lição de casa. Presidentes relativamente fracos (do ponto de vista constitucional), conexão eleitoral partidária, partidos institucionalizados e poucos partidos com representação congressual possibi- 
litariam o bom funcionamento do presidencialismo argentino. $\mathrm{O}$ caso brasileiro aparece na literatura como o pior dos mundos. A combinação de presidencialismo com representação proporcional de lista aberta, partidos fracos e a fragmentação parlamentar impossibilitaria ao Executivo formar maioria congressual estável, forçando-o a utilizar mecanismos unilaterais de governo (medidas provisórias - MPs), colocando em risco a estabilidade democrática. A tensão entre os poderes seria estrutural ao sistema presidencialista brasileiro. O quadro a seguir mostra a comparação entre as macrovariáveis institucionais que seriam determinantes na performance das democracias presidencialistas.

\begin{tabular}{|l|c|c|}
\cline { 2 - 3 } \multicolumn{1}{c|}{} & Quadro 1 \\
\cline { 2 - 3 } \multicolumn{1}{c|}{} & Argentina & Brasil \\
\hline Sistema eleitoral & lista fechada & lista aberta \\
\hline Partido & forte & fraco \\
\hline Fragmentação & baixa & alta \\
\hline Executivo $^{3}$ & fraco & forte \\
\hline
\end{tabular}

Elaboração do autor.

As evidências empíricas utilizadas pela literatura para mensurar a dinâmica da produção legislativa de um sistema político são: a dominância legislativa - que se refere ao controle da atividade legislativa entre os poderes, visualizada a partir da origem do total das medidas aprovadas; a taxa de sucesso - encontrada através da proporção dos projetos aprovados em relação ao total de projetos enviados pelo governo, $\mathrm{o}$ indicador ideal da capacidade governativa do Executivo; e o grau de disciplina partidária - a capacidade dos partidos em coordenar e controlar o comportamento dos legisladores individuais, usualmente medida pelo índice de Rice ${ }^{4}$.

Do ponto de vista da literatura institucionalista comparada, o cotejo dos dados da Argentina com os números para o caso brasileiro deveria apontar para a maior capacidade governativa do Executivo na Argentina. Não é isso que os dados mostram. A produção legislativa na Argentina está dividida entre os dois poderes. Os dados apresentados por Molinelli, Palanza e Sin (1999:438) indicam que cerca de 50\% da legislação aprovada entre 1983 e 1997 é originária do Executivo. Durante o governo Carlos Menem, o Legislativo aprovou mais medidas do que o Executivo (56,5\% contra 44,5\%). Este quadro não se altera se incluir- 
mos os decretos de necessidade e urgência - DNUs ${ }^{5}$. Negretto ${ }^{6}$ (2004:553) mostrou que, entre 1983 e 1999, a produção legislativa esteve equilibrada entre os dois poderes. A inclusão dos DNUs torna o Executivo o ator com mais preponderância legislativa, ainda que o Legislativo tenha sido um ator competitivo durante todo o período. O Executivo conseguiu seu nível máximo durante o primeiro governo Menem (58\% contra 44\%).

Vejamos as evidências do caso brasileiro. De acordo com o levantamento da produção legislativa desenvolvido pelo Centro Brasileiro de Análise e Planejamento - Cebrap, o Executivo é o grande legislador do sistema político brasileiro. A capacidade de iniciar legislação do Legislativo é irrisória, não havendo espaço para que os interesses institucionais (leia-se defesa de interesses paroquiais) do Congresso se materializem na produção legal, afinal, $86 \%$ das leis aprovadas no período foram de iniciativa do Executivo, e somente $14 \%$ das leis aprovadas tiveram origem no Legislativo.

No que diz respeito às taxas de sucesso do Executivo, as evidências empíricas também sinalizam para um quadro contrário ao esperado pela literatura. No período entre 1983 e 1997, a taxa média de sucesso do governo no sistema político argentino foi de 60\% (Molinelli, Palanza e Sin, 1999:434). O contraste com o caso brasileiro, ainda que de menor magnitude do que nos índices de dominância, é claro. O banco de dados legislativos do Cebrap indica que a taxa de sucesso do governo entre 1989 e 2000 foi de 72,7\%. O menor índice do governo foi $65,6 \%$, alcançado no período Fernando Collor, número maior que a média do governo na Argentina. Os números mais relevantes, todavia, dizem respeito ao paradoxo argentino. Trata-se da coexistência de altas taxas de disciplina partidária e sucesso relativamente fraco do Executivo ${ }^{7}$. Esse é o dilema a ser explicado. As baixas taxas de sucesso do governo não se devem à baixa disciplina partidária do seu partido no Legislativo. Vejamos os números para o governo Menem.

As variáveis explicativas encontradas na literatura associam o desempenho do governo a dois fatores essenciais: o tamanho do partido (base) do presidente e a capacidade das lideranças partidárias de garantir a cooperação dos legisladores individuais. Assim, há uma associação esperada entre partidos disciplinados e presidentes com altas taxas de sucesso legislativo. Em minha leitura, a combinação de partidos altamente disciplinados e baixa taxa de sucesso que caracterizam a 
Tabela 1

Coesão do Partido Governista e Taxa de Sucesso do Executivo (Governo Menem)

Índice de Rice e Taxa de Sucesso do Executivo

(1989-1997)

\begin{tabular}{l|c|c}
\hline Período & $\begin{array}{c}\text { Disciplina PJ* } \\
\text { (Índice de Rice) }\end{array}$ & $\begin{array}{c}\text { Taxa de Sucesso } \\
\%\end{array}$ \\
\hline $1989-1991$ & 94,0 & 56,0 \\
$1991-1993$ & 97,0 & 62,0 \\
$1993-1995$ & 98,0 & 66,0 \\
$1995-1997$ & 97,0 & 61,0 \\
\hline
\end{tabular}

Fontes: Jones et alii (2002:156) ${ }^{8}$; Molinelli, Palanza e Sin (1999:434).

*Partido Justicialista.

produção legislativa mostra que a influência das variáveis externas ao processo decisório não necessariamente atua no sentido de garantir maior sucesso ao governo. Em outras palavras, as macrovariáveis institucionais do sistema político argentino incentivam o comportamento disciplinado dos partidos políticos. Assim, a relativa baixa capacidade de sucesso do Executivo argentino não se deve a fatores exógenos ao processo decisório, mas está relacionada, como veremos na seção seguinte, com a incapacidade do Executivo argentino de controlar os mecanismos de alteração do timing do processo legislativo.

Em suma, a comparação da produção legislativa entre Argentina e Brasil, bem como o paradoxo argentino, sugerem a necessidade de observarmos a organização interna do processo decisório para um melhor entendimento dos determinantes do sucesso presidencial. A distribuição do poder de agenda parece ser uma importante variável tanto no entendimento da comparação da produção legislativa entre Argentina e Brasil, como da relativa baixa taxa de sucesso presidencial na Argentina, a despeito dos partidos políticos disciplinados.

\section{O PROCESSO DECISÓRIO NA ARGENTINA}

O sistema político argentino combina presidencialismo com representação proporcional pré-ordenada pelos partidos políticos, usualmente chamada de lista fechada. De acordo com Jones et alii (2002), os líderes partidários locais seriam os principais atores na definição da ordem dos candidatos no interior de cada lista. Os distritos eleitorais nas eleições proporcionais em âmbito federal confundem-se com os territórios dos estados (23 províncias mais a capital federal). Há um número fixo 
de deputados por províncias (cinco deputados), delimitado constitucionalmente. Os deputados são eleitos para um mandato de quatro anos; porém, a renovação para a Câmara dos Deputados (metade das cadeiras) ocorre a cada dois anos, o que significa dizer que a renovação parcial da bancada legislativa não coincide com as eleições presidenciais.

A Constituição argentina, no art. 77, estabelece a faculdade para as duas casas legislativas e para o Executivo iniciarem o processo da produção legal do país. A transformação de um projeto em lei deve necessariamente passar pelo crivo desses três atores (art. 78). Um projeto de lei, quando aprovado pela casa inicial, passa à Câmara revisora, que possui três opções: rejeitar todo o projeto, aprovar com a redação proposta pela Câmara que iniciou o processo ou aprovar com modificações. No primeiro caso, o projeto rejeitado será engavetado, não podendo ser reapresentado no mesmo ano legislativo (art. 81). Se a Câmara revisora aprovar o projeto em sua redação original, ele segue para a sanção do Executivo, que pode aprová-lo e, nesse caso, o projeto está pronto para ser convertido em lei, ou vetá-lo e enviá-lo com observações de volta para a Câmara que iniciou a tramitação. A Constituição estabelece maioria qualificada (dois terços dos membros) para que o projeto reinicie o processo de tramitação. Se ambas as câmaras aprovam a mesma versão, o projeto segue para o Executivo sancioná-lo sem direito a veto. Nos casos em que a Câmara revisora modifica a versão oriunda da Câmara inicial, o projeto retorna à primeira casa, que delibera em cima das modificações introduzidas. Se estas forem introduzidas por maioria qualificada (dois terços dos membros), a Câmara inicial pode insistir na redação original somente com maioria qualificada ou aceitar as modificações mediante a aprovação de projeto por maioria absoluta dos membros (art. 81). É importante ressaltar que a casa que iniciou a tramitação não poderá engavetar um projeto que tenha sido alterado pela Câmara revisora (art. 81). Isto insere no sistema uma lógica mais consensual, na medida em que força a cooperação entre as duas casas.

A Carta Constitucional argentina confere ao Executivo o poder de alterar o status quo de maneira unilateral. De acordo com o art. 99, terceiro parágrafo: "somente quando circunstâncias excepcionais tornarem impossível seguir o trâmite ordinário previsto pela Constituição para a sanção de leis e não tratarem de normas que regulem matéria penal, tributária, eleitoral ou regime dos partidos políticos poderá emitir decretos de necessidade e urgência [...]" (tradução do autor). 
As regras de aprovação dos DNUs estabelecem que o Executivo (chefe de gabinete) deve submeter o decreto ao Congresso, que analisará seu mérito através de uma comissão bicameral. A comissão tem 10 dias para enviar o projeto à votação do plenário. O Poder Legislativo não tem capacidade de emendar os DNUs, a votação em plenário é para aprovação ou rejeição do decreto de forma integral. As possíveis modificações em matérias reguladas pelos DNUs são feitas por projetos de lei que seguem o ritual ordinário de aprovação' Contudo, a regulamentação em caso do não-cumprimento desse prazo não está prevista na Constituição. Assim, o que prevalece é a prática anterior à incorporação dos DNUs ao texto constitucional. Se o Congresso não se pronunciar nesse período, está implícita sua aprovação; trata-se de um mecanismo de aprovação tácita (Negretto, 2004).

A Constituição argentina, diferentemente do caso brasileiro, não prevê nenhum monopólio de legislação para o Executivo em nenhuma área $\left(\right.$ art. 61) ${ }^{10}$. De acordo com Figueiredo e Limongi (1999; 2000), áreas de iniciativa exclusiva são importantes instrumentos do Executivo no controle da agenda, pois não é possível alteração no status quo que não seja da preferência do presidente. Ainda, não há no caso argentino previsão constitucional sobre alteração no ritmo de tramitação de um projeto de lei, diversamente do caso brasileiro, que prevê a faculdade do Executivo em pedir tramitação urgente para seus projetos; em circunstâncias assim, o Legislativo deverá se manifestar sobre a proposição no prazo de 45 dias (art. 64), reforçando seu poder de agenda setting.

Em linhas gerais, o processo legislativo no interior da Câmara dos Deputados na Argentina está organizado em torno dos blocos parlamentares. Cada bloco é composto por pelo menos três legisladores, e seus presidentes possuem uma série de recursos, tais como: indicação de deputados para as comissões especializadas, recursos orçamentários e de assessoria e participação na definição da agenda. Fundamentalmente, os dois principais lócus de decisão do processo legislativo na Argentina são a Comisión de Labor Parlamentaria - CLP e as comissões especializadas. É a CLP, composta pelo presidente da Câmara, os vice-presidentes e os líderes dos blocos partidários, que definirá os temas a serem tratados no plenário. Em relação ao processo de formação das comissões, do ponto de vista legal, quem faz a distribuição dos assentos é o presidente da Casa; contudo, essa indicação respeita sempre as preferências dos líderes partidários, representando o tamanho da bancada de cada bloco. O presidente, em consulta com os líderes parti- 
dários, define como ficarão distribuídos os postos de lideranças das comissões, não havendo restrição à participação dos deputados em mais de uma comissão simultaneamente.

Gostaria de chamar atenção para dois elementos fundamentais à compreensão do processo de definição da agenda no sistema político argentino. No meu entender, as regras do jogo estão desenhadas de maneira a permitir o conflito entre os dois poderes na iniciativa da produção legal. A Constituição não estabelece com clareza qual poder é o agenda setter, ou seja, é contraditória na definição do ator responsável pelo controle da atividade legislativa. Se, por um lado, ela garante ao Executivo tanto poderes pró-ativos (poder de emitir decretos com força de lei) quanto reativos (poder de veto com maioria de dois terços para que seja derrubado) - o que deixaria o Executivo em posição privilegiada vis-à-vis o Legislativo -, ela não determina o mecanismo de urgência constitucional que garantiria privilégios na tramitação dos projetos enviados pelo Executivo, tampouco atribui prerrogativas exclusivas. Assim, tanto o Executivo como o Legislativo não conseguem ser os atores preponderantes na definição do timing e da natureza das matérias a serem discutidas.

De forma geral, os modelos teóricos encontrados na literatura fazem a contraposição entre processo decisório descentralizado, isto é, sistemas nos quais as comissões são os atores preponderantes na definição da agenda, e sistemas centralizados nos quais a agenda é definida por um agente central, representante da maioria, seja ela do plenário ou do partido majoritário (Krehbiel, 1991; Cox e McCubbins, 1993; 1995).

Na dicotomia presente nessa literatura (Cox, 1987; Figueiredo e Limongi, 1999; 2000; Cheibub e Limongi, 2002), a disciplina partidária e o sucesso legislativo caminham na mesma direção. Nos sistemas centralizados, os líderes partidários teriam recursos disponíveis para punir o comportamento não-cooperativo dos parlamentares rank and file. O espaço para atuação indisciplinada dos parlamentares é mínimo. A estratégia de não-cooperação implicaria na incapacidade de os parlamentares obter recursos necessários para sua reeleição. Além disso, o controle da agenda permitiria ao Executivo e aos líderes partidários controlarem o timing do processo legislativo, colocando em pauta apenas os assuntos consensuais entre os membros da base (partido) governista, garantindo assim a coesão partidária e apoio ao Executivo. Nesses sistemas, o Executivo aparece como o legislador efetivo, pois a tra- 
mitação de seus projetos contaria com privilégios, sendo sua aprovação muito menos custosa se comparada às iniciativas individuais dos parlamentares.

Em contrapartida, nos processos decisórios descentralizados, as comissões seriam atores autônomos na definição dos temas passíveis de modificação, funcionando com poderes de veto, bem como no timing do processo. O processo de auto-seleção na composição das comissões permitiria aos legisladores construírem sua relação com os eleitores à margem da atuação partidária. Os parlamentares escolheriam a comissão que serviria aos interesses de sua base eleitoral, moldando seu vínculo pessoal. Assim, os cargos e recursos no interior do Legislativo não seriam monopólios dos líderes partidários.

Nesses casos, os líderes partidários e o Executivo não teriam os instrumentos necessários para recompensarem o comportamento partidário dos parlamentares. Em outras palavras, faltariam mecanismos que garantissem tanto a coesão (através do controle da agenda) como a disciplina (controle dos benefícios intralegislativos) dos parlamentares. Haveria, então, uma associação entre sistema descentralizado e participação efetiva do Poder Legislativo na produção de políticas públicas, já que o Executivo não contaria com nenhum privilégio na aprovação das matérias. O resultado desse processo seria indisciplina partidária e falta de suporte legislativo às medidas do Executivo (Cain, Ferejohn e Fiorina, 1987).

O processo de definição da agenda nos sistemas políticos decorre, fundamentalmente, de duas variáveis: as preferências dos atores e as regras institucionais (Shepsle, 1979). A idéia, neste artigo, é analisar os mecanismos de alteração no ritmo do processo legislativo. A escassez de tempo é uma grande arma nas mãos do órgão central para controlar a agenda (Cox e McCubbins, 1993). A literatura sobre o caso brasileiro (Figueiredo e Limongi, 1999) mostrou que o regime especial de tramitação é fundamental para agilizar a aprovação de um projeto de lei, pois esvazia os trabalhos das comissões que são o principal espaço de participação dos parlamentares no processo de formulação de políticas.

Do ponto de vista formal, o principal mecanismo para o caso argentino é o tratamiento sobretablas. Este expediente funciona como um importante atalho do processo legislativo, pois leva à votação, na mesma sessão, qualquer matéria, tenha ou não a comissão emitido um dictamén. De acordo com o art. 134 do regimento da Câmara: "é moção sobretablas 
toda proposição que tenha por objetivo um assunto na mesma seção tenha ou não um relatório da comissão" (tradução do autor). Os deputados podem requerer esse tipo de tratamento durante meia hora no início das sessões legislativas. A aprovação do requerimento requer o suporte de dois terços dos parlamentares, nesses casos, o projeto será o primeiro a ser tratado na ordem do dia.

Outro expediente importante na definição do ritmo do trâmite legislativo é a moção de preferência. Ele permite o tratamento do tema em uma data definida ou na sessão seguinte como o primeiro assunto da ordem do dia sem haver necessariamente o pronunciamento da comissão. Se o projeto tiver o parecer das comissões, é necessária maioria absoluta dos membros para aprovação, caso contrário, o pedido de urgência é aprovado somente mediante o apoio de dois terços dos membros.

Nossa base de dados consiste na tramitação dos projetos de lei aprovados na Argentina, excluindo-se a aprovação dos DNUs, entre dezembro de 1983 e outubro de 1998. Foram levantados 1.834 projetos de lei. A análise empírica aqui desenvolvida deverá dar evidências a duas questões, quais sejam, o principal lócus de negociações políticas e alterações nos projetos de lei no sistema político argentino e em que medida os recursos de tramitação especial são utilizados. Qual a origem desses projetos? Afirmo que se a maioria das alterações de um projeto se dão na comissão, os mecanismos de tramitação especial são fundamentais no entendimento do sucesso legislativo do governo.

Vejamos o que acontece com um projeto no interior do Legislativo. Em primeiro lugar, concentrar-me-ei na relação entre comissão e plenário, para verificar a semelhança nas preferências entre esses dois momentos do processo legislativo. Quando as comissões têm suas preferências respeitadas pelo plenário, tem-se um dos componentes de uma estrutura descentralizada dos trabalhos legislativos. Os números estão na Tabela 2.

Os dados mostram que a participação do Poder Legislativo na definição das políticas públicas é relativamente pequena. A maioria $(59,9 \%)$ da produção legislativa no período passou no Legislativo sem sofrer nenhum tipo de alteração. Os números mostram que as comissões, à primeira vista, são o principal lócus das discussões e resoluções dos conflitos intrapartidários. Do total aprovado, um quarto dos projetos sofreu alterações, ao passo que a participação do plenário foi irrisória $(8,3 \%)$. Se excluirmos os projetos referentes a acordos internacionais 
Tabela 2

Modificação dos Projetos Aprovados

(1983-1998)

\begin{tabular}{l|c}
\hline Instância & $\mathbf{N}^{\mathbf{0}}$ \\
\hline Comissão & 464 \\
& $(25,2 \%)$ \\
Plenário & 117 \\
& $(6,3 \%)$ \\
Comissão + plenário & 153 \\
Sem alteração & $(8,3 \%)$ \\
& 1.100 \\
Total & $(59,9 \%)$ \\
& $\mathbf{1 . 8 3 4}$ \\
\hline
\end{tabular}

Fonte: www.diputados.gov.ar. Dados compilados pelo autor.

$(n=536)$, a porcentagem de projetos aprovados com modificações nas comissões sobe para 35,5\% $(n=464)$. Se considerarmos os projetos que sofreram alterações na comissão e no plenário, veremos que o total de projetos aprovados que foram alterados representa $45,7 \%$, um número não desprezível.

Entretanto, não é possível, a partir desses números, verificar se as preferências das comissões estão sendo respeitadas no plenário. Para resolver essa questão, examinarei mais de perto os projetos aprovados com alterações.

Tabela 3

Projetos Aprovados com Modificação por Origem (1983-1998)

\begin{tabular}{l|c|c|c}
\hline Instância & Executivo & Legislativo & Total \\
\hline Comissão & 124 & 340 & 464 \\
& $(57,6 \%)$ & $(66,7 \%)$ & $(63,2 \%)$ \\
Plenário & 36 & 71 & 117 \\
& $(16,7 \%)$ & $(13,9 \%)$ & $(15,9 \%)$ \\
Comissão + plenário & 55 & 98 & 153 \\
& $(25,7 \%)$ & $(19,4 \%)$ & $(20,9 \%)$ \\
\hline Total & $\mathbf{2 1 5}$ & $\mathbf{5 0 9}$ & $\mathbf{7 3 4}$ \\
& $\mathbf{( 1 0 0 \% )}$ & $\mathbf{( 1 0 0 \% )}$ & $\mathbf{( 1 0 0 \% )}$ \\
\hline
\end{tabular}

Fonte: www.diputados.gov.ar. Dados compilados pelo autor.

Os números mostram que o sistema de comissões não é apenas o espaço no qual os projetos são mais modificados, mas também tem suas 
preferências respeitadas pelo plenário. A maioria expressiva dos projetos foi modificada somente nas comissões $(63,2 \%)$, o que demonstra que o plenário aceita as modificações introduzidas nas comissões. A alta taxa de concordância com o plenário revela que o sistema de comissões é o principal lócus de negociação entre os partidos. Quando um projeto é aprovado na comissão, dificilmente é alvo de alterações. Em outras palavras, o crivo das comissões aumenta a probabilidade de aprovação de um projeto de lei.

O grosso das modificações recai sobre os projetos originários do Poder Legislativo. Apenas 29,2\% dos projetos modificados tiveram origem no Executivo, ao passo que 70,8\% foram iniciados por parlamentares. De acordo com argumento aqui exposto, isso não deveria ocorrer. Assumindo que a separação de propósitos no sistema político argentino é acentuada, deveríamos esperar que as modificações do Legislativo ocorressem nos projetos do Poder Executivo. Por que isso não ocorre? Minha explicação é que os projetos apresentados pelo Executivo são, em sua maioria - aproximadamente 62,3\% (536) do total-, acordos internacionais. Como a costura de acordos internacionais é exclusividade do Executivo, o Legislativo não possui subsídios para competir nessa área. A baixa taxa de alteração, assim, está menosprezada pela natureza de sua agenda.

Verifica-se na Tabela 4 se os projetos aprovados tiveram sua tramitação facilitada por algum expediente interno ao Legislativo.

Tabela 4

Projetos Aprovados sob Tramitação Especial por Origem

(1983-1998)

\begin{tabular}{l|c|c|c}
\hline Tipo de Requerimento & Executivo & Legislativo & Total \\
\hline Sobretablas & 154 & 321 & 475 \\
& $(17,8 \%)$ & $(32,9 \%)$ & $(25,8 \%)$ \\
Preferência & 28 & 55 & 83 \\
Sobretablas + preferência & $(3,0 \%)$ & $(5,2 \%)$ & $(4,5 \%)$ \\
& 33 & 78 & 111 \\
Nenhum & $(3,2 \%)$ & $(8,5 \%)$ & $(6,5 \%)$ \\
& 646 & 519 & 1.165 \\
Total & $(75 \%)$ & $(53,3 \%)$ & $(63,5 \%)$ \\
\hline
\end{tabular}

Fonte: www.diputados.gov.ar. Dados compilados pelo autor. 
Uma simples observação na freqüência de projetos aprovados sob regime de tramitação extraordinário mostra que tramitação especial na aprovação dos projetos na Argentina não é a regra. Vimos na Tabela 3 que o número de projetos aprovados que tramitaram sob regime especial é comparativamente pequeno. Apenas $36,8 \%$ das leis tiveram tramitação especial. O contraste com o caso brasileiro é marcante. Figueiredo e Limongi (1999:58) mostraram que, no período entre 1989-1994, das 514 leis aprovadas no Brasil, 282 (55\%) foram objetos de pedido de urgência. Ainda, apenas 159 (29\%) tiveram sua tramitação ordinária. Em contrapartida, na Argentina, 63,5\% das leis foram aprovadas sem nenhum expediente que acelerasse o processo legislativo.

Entre os expedientes expostos na Tabela 4, o que dá maior agilidade ao processo de tramitação é o tratamiento sobretablas, pois retira imediatamente o projeto da comissão, reduzindo sua capacidade de atuação, já que o mecanismo de preferência não garante necessariamente que o projeto seja votado na mesma sessão. O fato desse mecanismo ser pouco utilizado $(25,8 \%)$ significa que as comissões são rotas quase obrigatórias na aprovação de um projeto.

Vê-se na Tabela 3 que a capacidade do Executivo vis-à-vis o Legislativo em utilizar mecanismos que aceleram o processo legislativo é irrisória. Do total de projetos que tiveram sua tramitação facilitada (669), 32,1\% tiveram sua origem no Executivo. Além disso, $75 \%$ de seus projetos seguiram o ritmo de tramitação normal.

Se construirmos uma variável dicotômica - "tipo de tramitação" (tramitação especial ou tramitação) - a partir dos dados da Tabela 4 e fizermos um cálculo da razão de chance de um projeto do Legislativo sofrer alteração no ritmo de tramitação em relação aos projetos do Executivo, veremos que a possibilidade desta aceleração ocorrer é 2,63 vezes maior (ou $163,3 \%)$.

Os projetos oriundos do Executivo não possuem nenhum privilégio em sua tramitação, ou seja, ele não é capaz de determinar o timing do processo Legislativo ${ }^{11}$. A estrutura interna do Legislativo argentino garante espaço para que suas próprias medidas tenham privilégio na sua aprovação; $67,9 \%$ dos projetos aprovados foram originados dos próprios parlamentares. E mais, quase a metade $(46,7 \%)$ de seus projetos teve sua tramitação facilitada. O Legislativo, então, é superior ao Executivo na utilização desses expedientes, tanto em números absolutos (dominante) como em termos mais relativos (eficiente) ${ }^{12}$. 
O contra-argumento à minha leitura é que o Executivo utiliza tais instrumentos apenas nos projetos que lhe interessa acelerar a tramitação, utilizando, assim, seus recursos escassos para garantir um comportamento cooperativo dos parlamentares apenas nos projetos que ele considera importantes. De fato, os dados da Tabela 4 não permitem afirmar nada nesse sentido. Dessa forma, analisarei não os projetos aprovados com tramitação especial, mas a freqüência de uso desses expedientes por parte de cada Poder.

Se olharmos exclusivamente para o número de projetos aprovados, poderemos estar subestimando a capacidade dos atores em acelerar o ritmo de tramitação dos projetos, pois o mesmo projeto pode ter seu expediente modificado em diferentes momentos do processo Legislativo, ou seja, o mesmo projeto pode ter seu ritmo modificado mais de uma vez. Os dados da Tabela 5, contudo, não corroboram a hipótese de aumento da participação do Executivo no uso dos mecanismos para garantir a agilidade na aprovação dos projetos prioritários de sua agenda.

Tabela 5

Freqüência de Aprovação de Requerimentos Especiais por Origem (1983-1998)

\begin{tabular}{l|c|c|c}
\hline Tipo de Requerimento & Executivo & Legislativo & Total \\
\hline Sobretablas & 230 & 483 & 713 \\
& $(76,6 \%)$ & $(76,5 \%)$ & $(75,5 \%)$ \\
Preferência & 70 & 148 & 218 \\
& $(23,4 \%)$ & $(23,5 \%)$ & $(24,5 \%)$ \\
\hline Total & 300 & $\mathbf{6 3 1}$ & $\mathbf{9 3 1}$ \\
& $\mathbf{( 1 0 0 \% )}$ & $\mathbf{( 1 0 0 \% )}$ & $\mathbf{( 1 0 0 \% )}$ \\
\hline
\end{tabular}

Fonte: www.diputados.gov.ar. Dados compilados pelo autor.

O Executivo, em comparação ao Legislativo, continua sendo menos eficiente em agilizar os projetos. Do total de expedientes aprovados, apenas 32,2\% (300) recaíram sobre projetos do Executivo, o que reforça a natureza descentralizada do processo decisório na Argentina. É esta descentralização que torna a separação de poderes mais acentuada na Argentina em comparação ao caso brasileiro.

Esta não é a única leitura possível dos dados apresentados até aqui. Poder-se-ia argumentar que o Executivo é tão determinante na agenda legislativa que seus projetos não necessitariam de mecanismos extraordinários para sua aprovação. O número de cadeiras do partido presi- 
dencial seria suficiente para garantir uma relação harmoniosa entre os dois poderes. A baixa freqüência no uso desses expedientes refletiria, assim, o domínio e não a fraqueza do Executivo. Tal interpretação ignora as baixas taxas de sucesso legislativo do Executivo. Se o Executivo pudesse abrir mão desses expedientes especiais, não encontraríamos essas taxas tão baixas. Creio, portanto, que é patente a falta de capacidade do Executivo de controlar a agenda e, por esse expediente, garantir o controle sobre a produção legislativa.

Por fim, há ainda a hipótese de que esses expedientes não influenciam a aprovação de um projeto de lei. Em outras palavras, esses mecanismos não ajudariam a explicar o sucesso legislativo do Executivo. Assim, há a necessidade de verificar a associação entre aprovação sob regime especial e a taxa de sucesso do Executivo. A taxa de sucesso do governo Raúl Alfonsín foi maior do que durante o período do governo Menem (69\% x 56\%). Logo, se esses mecanismos são armas importantes no processo legislativo, deveríamos encontrar um uso maior deles por parte de Alfonsín. Vejamos, na Tabela 6, os resultados:

Tabela 6

Projetos do Executivo Aprovados com Requerimentos Especiais por Governo (1983-1998)

\begin{tabular}{l|c|c|c}
\hline Tipo de Requerimento & Alfonsín & Menem & Total \\
\hline Sobretablas & 68 & 86 & 154 \\
& $(21,4 \%)$ & $(15,8 \%)$ & $(17,5 \%)$ \\
Preferência & 11 & 17 & 28 \\
& $(3,4 \%)$ & $(3,1 \%)$ & $(3,3 \%)$ \\
Sobretablas + preferência & 13 & 20 & 33 \\
& $(4,1 \%)$ & $(3,6 \%)$ & $(3,8 \%)$ \\
Nenhum & 225 & 421 & 646 \\
& $(70,9 \%)$ & $(77,3 \%)$ & $(75,0 \%)$ \\
\hline \multirow{2}{*}{ Total } & $\mathbf{3 1 7}$ & $\mathbf{5 4 4}$ & $\mathbf{8 6 1}$ \\
& $\mathbf{( 1 0 0 \% )}$ & $\mathbf{( 1 0 0 \% )}$ & $\mathbf{( 1 0 0 \% )}$ \\
\hline
\end{tabular}

Fonte: www.diputados.gov.ar. Dados compilados pelo autor.

A associação esperada entre eficiência no uso dessas armas e uma maior taxa de sucesso do Executivo confirmou-se. Durante o governo Alfonsín, 28,9\% dos projetos do Executivo tramitaram sob regime especial, ao passo que, no período Menem, 22,5\% tiveram tramitação extraordinária. Em termos absolutos, a Tabela 6 mostra que, durante o governo justicialista, o Executivo foi mais eficiente em diminuir o tem- 
po de tramitação dos seus projetos. Isto é decorrência da duração do mandato de cada governo. Se calcularmos o número de projetos que tiveram sua tramitação acelerada pelo número de anos de governo, encontraremos que, no período Alfonsín, o Executivo teve uma média anual de projetos apreciados em regime especial de 16,7/ano; enquanto no governo Menem a média foi 12,9/ano. A razão de chance de Alfonsín ter um projeto aprovado em tramitação especial, em relação a Menem é 1,4 vezes, ou $40 \%$ maior. Assim, a razão do maior sucesso legislativo do governo Alfonsín passa pela utilização dos recursos que permitem influenciar o timing do processo legislativo. É verdade que o governo Menem foi muito mais habilidoso no uso dos DNUs; no meu entender, esse fato é menos um sinal de força governativa e mais de incapacidade (ou falta de vontade) de legislar por via ordinária.

O que os dados informam sobre a dinâmica legislativa do sistema político argentino e seu paradoxo - partidos disciplinados e governo com baixa taxa de sucesso?

A organização do processo decisório é composta basicamente de dois elementos: os poderes legislativos do Executivo e a estrutura interna do Poder Legislativo. São estes dois fatores que definirão o poder de agenda dos atores. Esses recursos institucionais determinarão a capacidade do Executivo para garantir a cooperação dos parlamentares, minimizando a separação de propósito entre os dois Poderes. $\mathrm{O}$ argumento é que os líderes partidários têm monopólio na distribuição dos cargos no interior do Legislativo. Em contrapartida, o Executivo não dispõe de poder de agenda para garantir a cooperação dos parlamentares.

A literatura (Mustapic, 2002; Jones et alii, 2002) mostrou que existe uma tendência no sistema político argentino para a criação de postos no interior do processo legislativo. Segundo Mustapic (2002:35), tanto a criação de instituições dos blocos parlamentares (aumento no número de presidentes, novos cargos etc.) como o aumento no número de comissões permanentes funcionam como incentivos seletivos para garantir a cooperação dos parlamentares. De fato, como demonstrado por Jones et alii (2002), as presidências das comissões são ocupadas fundamentalmente por parlamentares que possuem vínculos estreitos com as lideranças partidárias. De todo modo, o que gostaria de acentuar é que os postos intralegislativos - sejam nas comissões, sejam cargos nos blo- 
cos parlamentares - estão nas mãos dos líderes partidários. Esta é uma das razões que ajudam a explicar a elevada disciplina partidária.

As baixas taxas de sucesso, em minha interpretação, são decorrentes do baixo poder de agenda do Executivo, seja da perspectiva da dominância legislativa, seja do controle do ritmo da tramitação. Diferentemente do caso brasileiro, o Executivo não tem capacidade de interferir significativamente, pelo menos não do ponto de vista institucional, nos trabalhos legislativos. A organização do processo legislativo na Argentina é descentralizada. A retirada de um projeto da comissão sem sua apreciação é exceção, portanto, não há constrangimento temporal para atuação dos parlamentares nessa arena. As comissões representam, assim, o principal lócus de resolução de conflitos intrapartidários, visto que o grosso das modificações dos projetos se dão em seu interior. O que é ainda mais fundamental é que o plenário respeita as decisões das comissões, referendando a maioria expressiva das alterações.

As taxas de dominância legislativa revelam que o conteúdo da produção legal é dividido entre o Executivo e o Legislativo. Quanto ao timing do processo decisório, o que os dados mostraram é que grande parte dos instrumentos que facilitam a tramitação é utilizada nos projetos de origem do Poder Legislativo. Não há privilégios para medidas tomadas pelo governo. Assim sendo, os instrumentos nas mãos do presidente não são suficientes para alterar as preferências dos legisladores e garantir a cooperação entre eles. As baixas taxas de sucesso do Executivo, então, são decorrentes da sua falta de poder de agenda. Resta-me ainda expressar o vínculo entre poder de agenda e a cooperação. Que mecanismo permite ao Executivo transformar o controle da agenda em sucesso legislativo? Vejamos uma passagem do desenho da organização decisória no Brasil: "A organização interna dos trabalhos legislativos é, antes de tudo, marcada pela atuação do Executivo. O Poder Legislativo se encontra em posição tal que o Executivo é capaz de ditar o conteúdo, o tempo e o ritmo dos trabalhos no Congresso" (Figueiredo e Limongi, 1999:55).

A passagem anterior indica que o controle da atividade legislativa é determinante no processo de formulação de políticas. Isto é, o ator que detém poder de agenda é quem define como, quando e onde um projeto de lei será passível de alteração. No caso brasileiro, esse ator é o Executivo. Assim, se os parlamentares desejam ter alguma influência na 
formulação de políticas públicas no Brasil, eles devem ter um comportamento cooperativo com o governo, já que apenas pelos seus trabalhos no interior do Parlamento um parlamentar não é capaz de deixar sua marca na política. A estrutura interna do Legislativo brasileiro minimiza a participação do parlamentar individualmente.

É justamente essa ferramenta que está ausente no sistema político argentino. O Executivo não possui o controle sobre o processo de formulação de políticas públicas e não tem como criar incentivos para que os parlamentares cooperem. A influência do governo na agenda legislativa não é determinante, daí a falta de apoio às medidas oriundas do governo. O Legislativo é capaz de definir sua própria agenda, mas tal capacidade passa, fundamentalmente, pelas mãos dos líderes partidários, afinal, são eles que estão representados na CLP e possuem o controle para a nomeação das comissões. Os parlamentares do "baixo clero", se quiserem ter alguma participação na formulação de políticas, devem cooperar com os líderes partidários. Esta é a origem da elevada disciplina partidária no Legislativo argentino.

\section{CONCLUSÃO}

A análise do impacto do mecanismo de urgência na Argentina à luz da literatura sobre o caso brasileiro desenvolvida neste artigo teve como preocupações básicas aprofundar o conhecimento acerca do funcionamento das instituições políticas na Argentina ${ }^{13}$ e dialogar com a literatura comparada acerca da performance das democracias presidencialistas. A estratégia analítica aqui utilizada consistiu em um deslocamento das variáveis macro que formam o arcabouço institucional em direção ao mecanismo de controle da atividade dos parlamentares.

Meu argumento é que, a despeito das macrovariáveis (Quadro 1) encontradas na literatura comparada apontarem para a melhor performance do presidencialismo na Argentina vis-à-vis o caso brasileiro, os efeitos da separação de poderes são mais visíveis no caso argentino devido à descentralização do processo decisório. Essa separação de propósitos é evidenciada na dinâmica da produção legal no caso argentino. Contrariamente ao esperado pela literatura institucionalista (Shugart e Carey, 1992; Mainwaring e Shugart, 1997; Cox e McCubbins, 2001; Cox e Morgenstern, 2002), o sistema político brasileiro é mais eficiente, do ponto de vista da produção legal, do que o sistema político argentino. 
O presidente, no sistema político brasileiro, é o agente que domina a produção legal e possui taxas de sucesso significativamente superiores ao caso argentino. Ao controlar o processo de tramitação das políticas, o Executivo brasileiro é capaz de controlar o conteúdo e o timing da produção legal do sistema político, garantindo, assim, a cooperação dos parlamentares com as medidas oriundas do Executivo. A estratégia ótima dos parlamentares é atuar de maneira cooperativa com o Executivo; daí as taxas de sucesso relativamente altas no Brasil, sobretudo quando comparadas ao caso argentino.

Em contrapartida, no sistema político argentino, o Executivo é incapaz de controlar o ritmo da tramitação dos projetos de lei e, por conseqüência, não é capaz de superar os obstáculos gerados pela atividade das comissões permanentes, tornando mais vagaroso o processo de aprovação das políticas. Não é por acaso que o governo Menem recorreu sistematicamente aos DNUs, pois o rito ordinário aumenta a barganha dos parlamentares no interior das comissões, como demonstram as baixas taxas de sucesso, se comparadas ao caso brasileiro. A análise da produção legal argentina mostrou a importância do conteúdo do timing do processo legislativo. A fraqueza do Executivo não ocorre no momento das votações nominais - de fato, os partidos argentinos apresentam uma coesão quase perfeita -, mas na incapacidade de priorizar suas medidas em detrimento dos projetos oriundos do Legislativo.

Cox e McCubbins (2001) argumentam que a separação de poderes em si não leva necessariamente à paralisia decisória (indecisiviness). A separação de propósitos entre os poderes é o elemento que definirá em que medida há divergência entre os poderes. O propósito de cada poder é dado, fundamentalmente, pelo sistema eleitoral. Assim, em sociedades muito heterogêneas, que contam com um sistema eleitoral permissivo, os diferentes interesses dos grupos sociais estariam representados, e a separação de propósitos tenderia a ser muito mais acentuada. Deveríamos encontrar, então, um cenário prejudicial à governabilidade decorrente do impasse entre os poderes.

A baixa fragmentação é um pressuposto necessário para a boa performance do presidencialismo. Minha análise mostrou que parece não haver uma relação de causa entre o número de partidos e a performance legislativa. O Executivo no Brasil - comparativamente com o caso argentino - é um ator muito mais efetivo do ponto de vista da produção de políticas, mesmo se relacionado a um Parlamento fragmentado. 
A análise do caso argentino à luz dos achados para o caso brasileiro mostrou que a organização do processo legislativo pode ser outra variável capaz de reduzir os efeitos da separação dos poderes. O processo decisório centralizado pode funcionar como contraponto aos possíveis incentivos fragmentadores do sistema eleitoral, negando a essa diversidade de atores espaço na produção das políticas. A arena decisória não é essencialmente um simples reflexo da arena eleitoral.

Este estudo procurou sustentar a tese de que o diagnóstico sobre o desempenho dos sistemas políticos pode ser em grande medida distinto se não tomarmos essa associação como necessária. Se a leitura estiver correta, a organização do processo decisório deveria fazer parte das variáveis independentes na construção de modelos analíticos que tenham como objeto a comparação da performance do presidencialismo na América Latina. Meu argumento não afirma que os efeitos do sistema eleitoral (e o número de partidos) não são relevantes para o entendimento das relações entre os poderes. É evidente que, nas democracias, a formação de maiorias é essencial para o funcionamento do sistema. O que o modelo de agenda nos mostra é que maiorias podem ser construídas, visto que o ator que controla a agenda possui o controle sobre a formulação de políticas e, portanto, tem instrumentos para garantir a cooperação necessária para a tomada de decisões. O caso brasileiro é paradigmático. Dada a fragmentação partidária, o partido do presidente obtém uma parcela pequena do número de cadeiras, insuficiente para garantir a governabilidade. Contudo, os poderes de agenda e sua capacidade de distribuir benefícios seletivos permitem ao Executivo montar uma coalizão de governo estável que consegue evitar o cenário de paralisia decisória. Presidencialismos podem formar e formam coalizões de governo (Figueiredo e Limongi, 1999; Cheibub e Limongi, 2002; Cheibub, Przeworski e Saiegh, 2002).

A questão é saber por que os presidentes argentinos apoiados por partidos que contam com um número de cadeiras proporcionalmente maior do que no caso brasileiro têm menor sucesso? Minha interpretação é que o número reduzido de partidos efetivos na Argentina dificulta a obtenção de apoio nos demais partidos. Não há espaços para partidos satélites que, devido a sua baixa capacidade eleitoral, gravitam em torno do Executivo. O recorte governo/oposição é mais nítido.

Do ponto de vista analítico, o estudo mostrou que o modelo de agenda não é simplesmente uma explicação ad hoc para o funcionamento do 
caso brasileiro e deve ser incorporado de maneira mais sistemática pela literatura comparada. Esse procedimento joga luz em elementos pouco ressaltados pela literatura. O exame dos mecanismos de tramitação especial é apenas um recorte possível, e espero que mais trabalhos caminhem nessa direção.

A discussão desenvolvida ao longo do artigo possui algumas implicações para a agenda das reformas institucionais presente em partes significativas dos países latino-americanos. Ora, se a organização do processo decisório importa para o padrão de produção legislativa e, conseqüentemente, para a governabilidade e a natureza da representação de um sistema político, parte das demandas por melhorias no desempenho das democracias presidencialistas podem ser decorrentes do formato dessas instituições menos visíveis.

(Recebido para publicação em janeiro de 2007) (Versão definitiva em julho de 2007)

\section{NOTAS}

1. Morgenstern (2002:5) aponta três "olhares" sobre o Legislativo tomado como variável dependente: as relações Executivo-Legislativo; os partidos políticos e a estrutura interna do Legislativo; e a produção de políticas públicas.

2. A grande contribuição de Shugart e Carey para o debate foi a incorporação do impacto do calendário eleitoral na natureza das relações entre os poderes. A simultaneidade ou não das eleições para o Legislativo e para o Executivo é determinante para o número de partidos no Legislativo que, em última instância, irá definir o caráter do mesmo. Na verdade, os autores discutem os efeitos sobre os poderes legislativos do Executivo; contudo, tais poderes seriam prejudiciais à governabilidade, dado seu caráter antagônico.

3. Não há um consenso na literatura sobre a força relativa dos poderes de agenda em perspectiva comparada na América Latina. Aqui, trato o Executivo argentino como mais fraco que o brasileiro, dada sua impossibilidade de alterar o processo de tramitação de um projeto de lei e a ausência de prerrogativas exclusivas em determinada área de políticas. Voltarei a esse ponto mais adiante. Para uma leitura diferente da empregada neste artigo, ver Shugart e Haggard (2001) e Morgenstern (2002).

4. O índice de Rice é obtido subtraindo o número de parlamentares que votaram a favor de uma proposta do total de parlamentares que votaram contra.

5. Mecanismo que equivale às MPs no Brasil. Para mais detalhes, ver a próxima seção. 
6. O autor leva em consideração apenas os DNUs reconhecidos pelo governo.

7. A disciplina partidária entendida no seu sentido mais restrito, tal como o conceito aparece na literatura institucionalista. Trata-se do grau de semelhança do comportamento dos atores em plenário medido nas votações nominais. As baixas taxas de sucesso do Executivo na Argentina expressam a falta de cooperação entre o governo e o partido no Legislativo. Esta é uma das lições do caso argentino: disciplina em plenário não está necessariamente associada com cooperação em outros momentos do processo legislativo.

8. Os números de votações nominais que compõem a amostra dos autores são: 78 (1989-91); 48 (1991-93); 47 (1993-95); 45 (1995-97). Eles representam as votações nominais controversas, nas quais pelo menos $20 \%$ dos presentes votaram na opção derrotada. O total das votações nominais no período foram: 103 (1989-91); 66 (1991-93); 47 (1993-95); 64 (1995-97).

9. Agradeço ao parecerista anônimo de DADOS por chamar atenção para esse ponto.

10. A exceção é o processo orçamentário. O art. 100, §6, define que é prerrogativa do Executivo iniciar o processo de elaboração do orçamento submetendo o projeto de lei à apreciação do Poder Legislativo.

11. Isso não quer dizer que a influência do Executivo na definição da agenda no sistema político argentino seja desprezível. Seguindo o argumento de Moe e Howell (1999), uma das formas pelas quais o Executivo influencia a agenda legislativa se dá por mecanismos não-formais. Um institucionalismo hard é incapaz de detectar o poder do Executivo. Nesse sentido, o Executivo influenciaria a agenda legislativa devido a seu destaque na opinião pública. Meus dados não me permitem fazer inferências sobre o argumento.

12. A comparação não deve ser entre o Executivo e os parlamentares individualmente. Se tomados individualmente, o poder dos parlamentares na determinação da agenda congressual é inferior ao Executivo. Para a finalidade deste artigo, o cotejo deve ser feito no agregado, comparando as instituições do sistema político argentino.

13. Na verdade, análises agregadas não permitem mensurar o significado substantivo a respeito da natureza da produção legislativa. Análise do conteúdo substantivo dessa legislação pode oferecer diagnóstico distinto do caso argentino. Meu estudo não tem a pretensão de desvendar o caso argentino, mas tão-somente jogar luz em uma arena pouco explorada pela literatura especializada. 


\section{REFERÊNCIAS BIBLIOGRÁFICAS}

ALDRICH, John e ROHDE, David. (2000), "The Consequences of Party Organization in the House: The Role of the Majority and Minority Parties in Conditional Party Government", in B. John e R. Fleisher (eds.), Polarized Politics - Congress and the President in a Partisan Era. Washington, CQ Press.

AMORIM NETO, Octavio. (2006), Presidencialismo e Governabilidade nas Américas. Rio de Janeiro, Fundação Konrad-Adenauer/Editora FGV.

CAIN, Bruce, FEREJOHN, John e FIORINA, Morris. (1987), The Personal Vote: Constituency Service and Electoral Independence. Cambridge, Harvard University Press.

CAREY, John e SHUGART, Matthew Soberg. (1995), "Incentives to Cultivate a Personal Vote: A Rank Ordering of Electoral Formulas". Electoral Studies, vol. 14, no 4, pp. 414-439.

CHEIBUB, José Antonio e LIMONGI, Fernando. (2002), “Democratic Institutions and Regime Survival: Parliamentary and Presidential Democracies Reconsidered". Annual Review Political Science, no 5, pp.151-179.

CHEIBUB, José Antonio, PRZEWORSKI, Adam e SAIEGH, Sebastian. (2002), “Governos de Coalizão nas Democracias Presidencialistas e Parlamentaristas". Revista Brasileira de Ciências Sociais, vol. 45, no 2, pp. 187-218.

COX, Gary. (1987), The Efficient Secret - The Cabinet and the Development of Political Parties in Victorian England. Cambridge, Cambridge University Press.

e MCCUBBINS, Mathew. (1993), Legislative Leviathan - Party Government in The House. Berkeley, University of California Press.

. (1995), "Bonding, Structure and the Stability of Political Parties: Party Government in the House", in K. Shepsle e B. Weingast (eds.), Positive Theories of Congressional Institutions. Ann Arbor, Michigan University Press.

. (2001), "The Institutional Determinants of Economic Policy Outcomes", in S. Haggard e M. McCubbins (eds.), Presidents, Parliaments, and Policy. Cambridge, Cambridge University Press.

COX, Gary e MORGENSTERN, Scott. (2002), “Epilogue: Latin America's Reactive Assemblies and Proactives Presidents", in S. Morgenstern e B. Nacif (eds.), Legislative Politics in Latin America. Cambridge, Cambridge University Press.

DIERMEIER, Daniel e KREHBIEL, Keith. (2003), "Institutionalism as a Methodology". Journal of Theoretical Politics, vol. 15, no 2, pp. 123-144.

FIGUEIREDO, Argelina e LIMONGI, Fernando. (1999), Executivo e Legislativo na Nova Ordem Constitucional. Rio de Janeiro, Editora FGV.

. (2000), "Presidential Power, Legislative Organization and Party Behavior in the Legislature". Comparative Politics, vol. 32, pp. 151-170.

HUBER, John. (1996), Rationalizing Parliaments. Cambridge, Cambridge University Press.

JONES, Mark, SAIEGH, Sebastian, SPILLER, Pablo e TOMMASSI, Mariano. (2002), “Amateur Legislators-Professionnal Politicians: The Consequences of 
Party-Centered Electoral Rules in a Federal System". American Journal of Political Science, vol. 46, no 3, pp. 356-369.

KREHBIEL, Keith. (1991), Information and Legislative Organization. Ann Arbor, University of Michigan Press.

MAINWARING, Scott e SHUGART, Matthew. (1997), “Conclusion: Presidentialism and the Party System", in S. Mainwaring e M. Shugart (eds.), Presidentialism and Democracy in Latin America. Cambridge, Cambridge University Press.

MAYHEW, David. (1974), The Electoral Connection. New Haven, Yale University Press.

MOE, Terry e HOWELL, William. (1999), “The Presidential Power of Unilateral Action”. Journal of Law, Economics and Organization, vol. 15, no 1, pp. 132-179.

MOLINELLI, Guillermo, PALANZA, Valéria e SIN, Gisela. (1999), Congreso, Presidencia y Justicia en Argentina. Buenos Aires, Eudeba.

MORGENSTERN, Scott. (2002), “Towards a Model of Latin American Legislatures”, in S. Morgenstern e B. Nacif (eds.), Legislative Politics in Latin America. Cambridge, Cambridge University Press.

. (2004), Patterns of Legislative Politics - Roll Call Voting in Latin America and the United States. Cambridge, Cambridge University Press.

MUSTAPIC, Ana Maria. (2002), “Oscillating Relations: President and Congress in Argentina", in S. Morgenstern e B. Nacif (eds.), Legislative Politics in Latin America. Cambridge, Cambridge University Press.

NEGRETTO, Gabriel. (2004), “Government Capacity and Policy Making by Decree in Latin America". Comparative Political Studies, vol. 37, no 5, pp. 531-562.

SANTOS, Fabiano. (2003), O Poder Legislativo no Presidencialismo de Coalizão. Belo Horizonte/Rio de Janeiro, Editora UFMG/IUPERJ.

SHEPSLE, Kenneth. (1979), "Institutional Arrangements and Equilibrium in Multidimensional Voting Model". American Journal of Political Science, vol. 23, no 1, pp.27-59.

SHUGART, Matthew e CAREY, John. (1992), Presidentes and Assemblies: Constitutional Design and Electoral Dynamics. Cambridge, Cambridge University Press.

SHUGART, Matthew e HAGGARD, Stephan. (2001), "Institutions and Public Policy in Presidential Systems", in S. Haggard e M. McCubbins (eds.), Presidents, Parliaments and Public Policy. Cambridge, Cambridge University Press. 


\section{ABSTRACT}

The Impact of Urgency Mechanisms on Presidential Success. An Analysis of the Argentinean Case in the Light of Brazilian Experience

The purpose of the article is to measure, in the light of the Brazilian experience, the influence of the micro institutions regulating the Executive's governmental capacity in Argentine. The empirical basis informing the argumentation is the processing of the statutes approved by the Argentinean Legislative between 1983 and 1998. The empirical evidences showed that the proposed bills originated from the Executive do not have a special course in the Legislative, what reduces their chances of approval even in a context of disciplined parties, contrary to the expected by a substantial part of the compared literature in the area.

Key words: decision process; compared political institutions; urgency mechanism

\section{RÉSUMÉ}

L'Impact des Mécanismes d'Urgence dans le Succès Présidentiel. Analyse du Cas Argentin à la Lumière de l'Expérience Brésilienne

Dans cet article, on cherche à mesurer l'influence des micro-institutions qui règlent le processus décisionnel, sur la capacité de gouverner du pouvoir exécutif en Argentine à la lumière de l'expérience brésilienne. La base empirique de nos arguments est le type d'acheminement des projets approuvés par le pouvoir législatif argentin entre 1983 et 1998. Les résultats empiriques révèlent que les projets issus du pouvoir exécutif ne disposent pas d'un acheminement particulier, ce qui réduit leurs chances d'être approuvés même là où les partis sont disciplinés. Ces résultats contrarient ce qu'on trouve dans la plupart de la littérature comparée.

Mots-clé: processus décisionnels; institutions politiques comparées; mécanisme d'urgence 